\title{
Developmental Learning Disorders: From Generic Interventions to Individualized Remediation
}

\author{
David Moreau* and Karen E. Waldie \\ Centre for Brain Research, School of Psychology, The University of Auckland, Auckland, New Zealand
}

\section{OPEN ACCESS}

Edited by:

Giseli Donadon Germano, Universidade Estadual Paulista, Brazil

Reviewed by:

Rosa K. W. Kwok, University of Plymouth, UK Vera Lúcia Orlandi Cunha, Universidade Estadual Paulista, Brazi Adriana Marques De Oliveira,

Faculdade de Filosofia e Ciências/UNESP/Marilia, Brazil

*Correspondence:

David Moreau d.moreau@auckland.ac.nz

Specialty section:

This article was submitted to Educational Psychology, a section of the journal

Frontiers in Psychology

Received: 29 July 2015 Accepted: 24 December 2015 Published: 12 January 2016

Citation:

Moreau D and Waldie KE (2016) Developmental Learning Disorders:

From Generic Interventions

to Individualized Remediation.

Front. Psychol. 6:2053. doi: 10.3389/fpsyg.2015.02053
Developmental learning disorders affect many children, impairing their experience in the classroom and hindering many aspects of their life. Once a bleak sentence associated with life-long difficulties, several learning disorders can now be successfully alleviated, directly benefiting from promising interventions. In this review, we focus on two of the most prevalent learning disorders, dyslexia and attention-deficit/hyperactivity disorder (ADHD). Recent advances have refined our understanding of the specific neural networks that are altered in these disorders, yet questions remain regarding causal links between neural changes and behavioral improvements. After briefly reviewing the theoretical foundations of dyslexia and ADHD, we explore their distinct and shared characteristics, and discuss the comorbidity of the two disorders. We then examine current interventions, and consider the benefits of approaches that integrate remediation within other activities to encourage sustained motivation and improvements. Finally, we conclude with a reflection on the potential for remediation programs to be personalized by taking into account the specificities and demands of each individual. The effective remediation of learning disorders is critical to modern societies, especially considering the far-reaching ramifications of successful early interventions.

Keywords: developmental learning disorders, dyslexia, ADHD, cognitive remediation, neural correlates, fMRI, genetics, training interventions

\section{INTRODUCTION}

Learning disorders such as dyslexia and attention-deficit/hyperactivity disorder (ADHD) represent significant challenges for children, parents, and educators. These neurodevelopmental disorders cannot be explained by intellectual ability or an inadequate learning environment, but instead appear to be due to differences in underlying brain function (Lyon et al., 2003; Nicolson and Fawcett, 2008). Combined, they impair learning in approximately one in five children, with devastating repercussions on numerous aspects of their lives. Much knowledge has been gained recently by studying the neural correlates of learning disorders, leading to the identification of specific neural networks that are typically altered in individuals with learning difficulties (Raschle et al., 2011), yet questions remain regarding causal links between changes in neural activity and behavioral improvement (Goswami, 2015). For example, recent evidence suggests that shifts toward normal brain activity do not necessarily lead to improved performance (Clark et al., 2014). If corroborated, this is an important finding, because it suggests that normalization of neural activity might not be the primary goal, and that instead remediation programs should focus on the implementation of adequate compensatory strategies (Waldie et al., submitted). 
Overall, important caveats remain in current behavioral interventions - remediation programs need to identify and target the specific needs of each individual to maximize improvement and to facilitate learning. Here, we provide an overview of the neural and behavioral mechanisms underlying dyslexia and ADHD, and discuss the comorbidity of the two disorders. We then explore current trends in cognitive remediation, and in particular the promise of ecological interventions. Finally, we conclude with a discussion of personalized regimens and highlight their potential in the remediation of dyslexia and ADHD.

\section{DISTINCT CHARACTERISTICS OF DYSLEXIA AND ADHD}

Dyslexia is primarily associated with a core speech sound (phonological) deficit (notably the inability to translate letters and letter patterns into phonological forms), with additional impairments in naming speed and working memory (Démonet et al., 2004; McCrory et al., 2005). In particular, dyslexics suffer from an inability to mentally represent words and speech sounds, or to break down complex entities into discrete sounds (Ziegler and Goswami, 2005). It should be noted that an alternative hypothesis postulates that phonological deficits emerge from visuospatial difficulties (Gabrieli, 2009; Vidyasagar and Pammer, 2010), but this is not the dominant theory currently (Skoyles and Skottun, 2009). Regardless of the cognitive bases of the disorder, dyslexia is rooted in a well-documented dysfunction of the reading network at the neural level. In particular, functional magnetic resonance imaging (fMRI) studies point toward functional and structural abnormalities in left parietal and temporal areas involved in phonological processing (Temple, 2002; Démonet et al., 2004), with compensatory engagement of anterior systems around the inferior frontal gyrus and a posterior (right occipitaltemporal) system (Shaywitz et al., 2006; Waldie et al., 2013). For example, we have demonstrated that BOLD signal changes during lexical decision reveal striking differences in brain activity between typical readers and dyslexics (Waldie, 2002). The former consistently show a predominant activity in two areas of the left hemisphere, particularly in posterior (superior temporal) regions, whereas dyslexics display very limited left-brain activity, with significant activation only in the right inferior frontal cortex, probably as a compensatory system (Figure 1, Waldie, 2002).

Attention-deficit/hyperactivity disorder is characterized by excessive activity, short attention span and impaired inhibitory control (American Psychiatric Association [APA], 2013). Executive function deficits are common, including working memory, planning, sustained attention, inhibition, and interference control (Barkley, 1997; Overtoom et al., 2002). The main components of ADHD, attention deficit and hyperactivity, are sometimes used to differentiate between two subtypes, inattentive and hyperactive-compulsive (American Psychiatric Association [APA], 2013). Although not universal, this distinction is the most common in the scientific literature
(Butterworth and Kovas, 2013). Neuroimaging studies typically show decreased functioning in the dorsolateral prefrontal cortex and dorsal anterior cingulate cortex on tasks requiring inhibitory control (Rubia et al., 2005), as well as diminished activity on inhibitory tasks in the right inferior prefrontal cortex and in the precuneus and posterior cingulate cortex (Suskauer et al., 2008). In addition, imaging studies have revealed altered patterns of activation in ventrolateral prefrontal, parietal and striatal regions (Bush et al., 2005). Despite overall consistency, there are also tremendous discrepancies in findings from this literature (Bush et al., 2005), especially magnified by methodological shortcomings (e.g., lack of control group, small sample, uncorrected multiple comparisons). Yet regardless of these limitations, studies strongly support the hypothesis that ADHD symptoms are caused by core dysfunctions in the prefrontal cortex, the basal ganglia, and by the chemical imbalance of local neurotransmitters such as dopamine, epinephrine, norepinephrine and serotonin (Aron and Poldrack, 2005).

\section{COMORBIDITY OF DYSLEXIA AND ADHD}

Between 5 and $10 \%$ of the population experience severe difficulties with reading (dyslexia) or concentration/impulse control (ADHD, American Psychiatric Association [APA], 2013). While they are typically studied separately, dyslexia and $\mathrm{ADHD}$ occur together $30-50 \%$ of the time (Germanò et al., 2010), and only about $40 \%$ of children with dyslexia and $20 \%$ of children with ADHD present a single condition (Willcutt and Pennington, 2000a,b). Although their functional characteristics are different (Landerl et al., 2009), this line of work suggests that ADHD and dyslexia share similar underlying mechanisms (Czamara et al., 2013), and further evidence indicates that the deficits underlying both disorders are due to similar congenital neurological pathologies (Giedd et al., 1994; Waldie and Hausmann, 2010). The relation between dyslexia and ADHD might therefore be attributable to common causal influences that increase susceptibility to both disorders.

Dyslexia and ADHD share a common cognitive deficit in processing speed, and twin studies indicate that this shared weakness might arise from common genetic influences that increase susceptibility to both disorders (Willcutt et al., 2010). Shared neurological processes could also underlie reading difficulties and ADHD. In particular, a variation in cerebral lateralization related to language processing and executive functions may be a common neural mechanism. Neuroimaging studies of individuals diagnosed with dyslexia and ADHD support such a mechanism, showing reversed asymmetry of hemisphere structures among planum temporale, caudate nucleus and frontal lobes (Stefanatos and Wasserstein, 2001; Foster et al., 2002; Hoeft et al., 2007). Striatal dysfunctions have also been observed in both ADHD and dyslexia (Lou et al., 1990; Cubillo et al., 2012), and could help explain some instances of co-occurrence. 


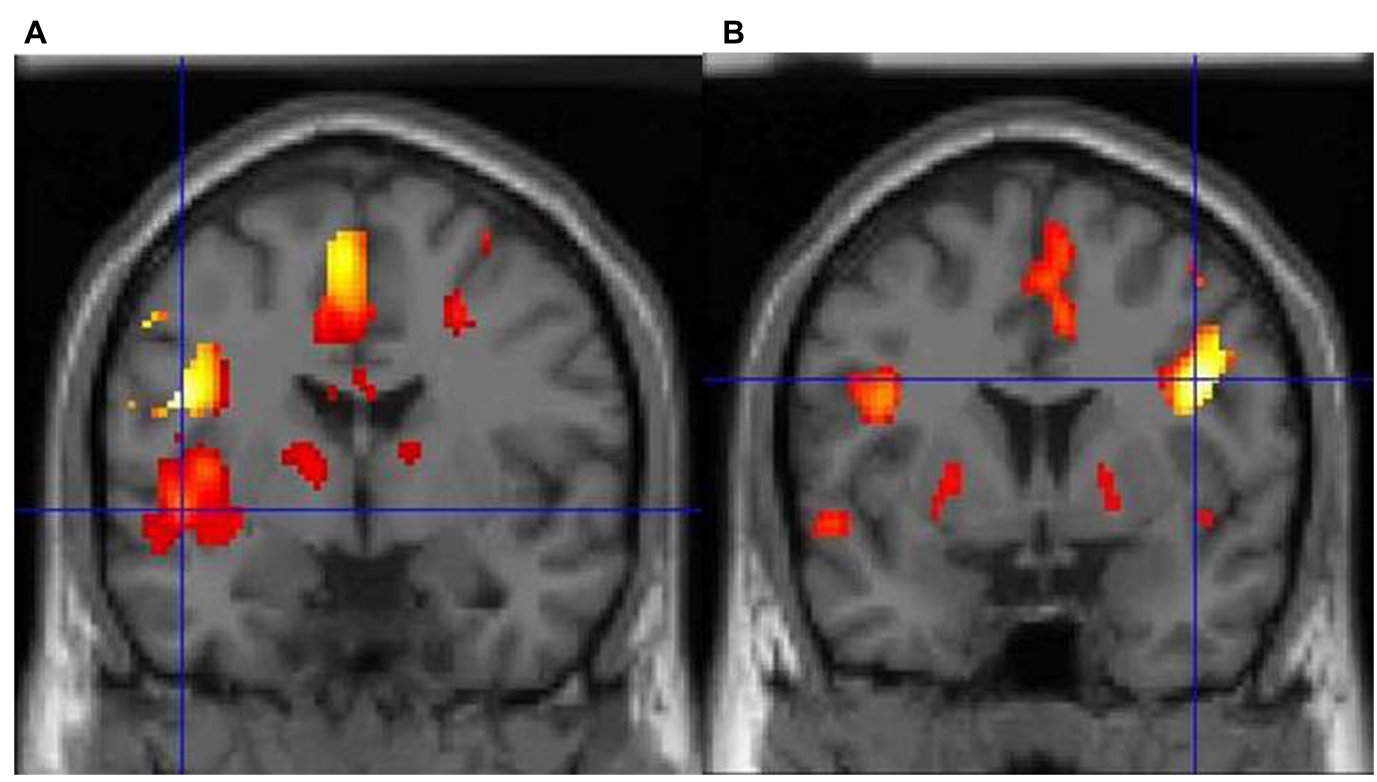

FIGURE 1 | (A) Typical adults show a predominance of activity in the left hemisphere during lexical decision-making with concrete nouns, particularly the left posterior superior temporal cortex (marked by the crosshair). (B) In contrast, adults with dyslexia show very limited left-brain activity and predominant activity in the right inferior frontal cortex.

\section{GENETIC AND ENVIRONMENTAL RISK FACTORS}

Besides neural correlates of comorbidity, significant advances have been made in understanding the extent to which dyslexia and $\mathrm{ADHD}$ are attributable to genetic or environmental influences. Several family and twin studies have demonstrated that both conditions are largely heritable (Shafritz et al., 2004; Willcutt et al., 2010); however, the two conditions are polygenetic, that is, a number of genes have small additive effects that contribute specifically to each learning disorder (Plomin et al., 2008). Heritability estimates for ADHD range from 70 to $80 \%$ and from 40 to $60 \%$ for dyslexia (Shafritz et al., 2004; Del'Homme et al., 2007). Targeted linkage, association analyses and genome scans have identified potential susceptibility sites that may increase the risk of these diagnoses. In particular, genome-wide linkage analyses of dyslexia and ADHD suggest some overlap between linkage regions, which might be explained by a single gene responsible for these disorders. These regions include $1 \mathrm{p} 36$, 2q22-35, 3p12-q13, 4q12-13, 6p21-22, 6q12-14, 13q22-33, and 15q15-21 (Castellanos and Tannock, 2002; Gayán et al., 2005; Galaburda et al., 2006; Caspi et al., 2008; Couto et al., 2010; Faraone and Mick, 2010; Gabel et al., 2010; Scerri and SchulteKörne, 2010).

Despite the genetic component of these learning disorders, heritable traits do not account for the full variance of their occurrence, leaving room for environmental factors and epigenetic interactions (Biederman, 2005; Ziegler et al., 2005). For example, DNA methylation and histone modification might play a critical role in these disorders, through their influence on gene regulation (Smith, 2011). Epigenetic processes guide cell differentiation and gene expression in early development, and several studies suggest that alterations can cause important cognitive deficits later in life (Gabel et al., 2010; Poelmans et al., 2011). Importantly, genetic and environmental factors may also relate to dyslexia and ADHD through vulnerability traits or unobservable characteristics of the disorders (Castellanos and Tannock, 2002), therefore obscuring observable causal mechanisms. As such, the comorbid phenotype may result from the overlap of risk factors, producing a high rate of co-occurrence. Regardless of current limitations in our understanding of these underlying mechanisms, neuroimaging and behavioral genetic studies are versatile and powerful approaches to examine the etiology and comorbidity of individual disorders - together, these studies support a partly shared genetic etiology between dyslexia and ADHD.

\section{EARLY DETECTION AND REMEDIATION}

Advances in our understanding of both dyslexia and ADHD have allowed earlier diagnoses, and represent promising tools to inform intervention programs. Imaging findings are particularly informative in this regard, as they provide critical information about typical patterns of activity across developmental stages. For example, studies have consistently indicated that skilled reading relies primarily on a left-lateralized cortical network including frontal, temporoparietal, and occipitotemporal areas (Rumsey et al., 1997; Turkeltaub et al., 2003; Cohen and Dehaene, 2004; Pugh, 2006; Richlan, 2012), yet it is important to note that this lateralized network is preceded by more bilateral patterns of activation when learning to read (Szaflarski et al., 2006). Eventually, such bilateral activation subsides, in favor of more 
lateralized and efficient networks highly optimized for reading (Shaywitz et al., 2007). Similarly, executive functions are typically poor in children and adolescents (Blakemore and Choudhury, 2006), and are among the last to develop due to different rates of cortical maturation (Stiles and Jernigan, 2010). Later stages of development allow maturation of prefrontal areas (Gogtay et al., 2004), which are critical in enabling and supporting executive functions (Alvarez and Emory, 2006). Therefore, in both reading and cognitive control processes, initial neural activity can roughly be characterized as disorganized and inefficient, but eventually transitions toward better system efficiency (Laughlin and Sejnowski, 2003).

This transitional phase at the core of the reading network or the attention network is typically defective in individuals affected by dyslexia and ADHD, respectively (McCrory et al., 2005; Shaw et al., 2007). As a consequence, the use of neuroimaging techniques to identify dysfunction in these networks is a promising diagnostic tool, and such differences in neural structure and activity have been used to predict long-term outcomes in dyslexia (Hoeft et al., 2011). These neural signatures of dyslexia and ADHD also suggest that restoration of normal brain activity could alleviate or remediate these disorders. However, it is important to acknowledge that the identification of neural correlates of dyslexia and ADHD does not necessarily imply that normalizing neural activity or brain structure should be the sole focus of remediation programs, as compensatory mechanisms have also been shown to participate in behavioral improvement (e.g., Eden et al., 2004). With this limitation in mind, it remains the case that early detection has the potential to allow correcting dysfunction of these networks before they are well established and automatic. However early, accurate diagnoses do not guarantee that individuals will not experience reading or attention/hyperactivity problems if the causes are latent or immune to behavioral remediation, but this approach has the potential to be more effective than later interventions due to increased cortical plasticity in early age (Merzenich et al., 1996).

TABLE 1 | Future challenges in the cognitive remediation of dyslexia and ADHD.

\begin{tabular}{|c|c|}
\hline Goal & Means \\
\hline Detection & $\begin{array}{l}\text { Improve early diagnosis of dyslexia and ADHD through the } \\
\text { combination of known risk factors and detailed mapping of } \\
\text { neural correlates (e.g., via EEG, MEG, fMRI, DTI). }\end{array}$ \\
\hline Personalization & $\begin{array}{l}\text { Increase the effectiveness of remediation programs by using } \\
\text { diagnostic data (e.g., behavioral, neural, genetic) to inform } \\
\text { training content in a continuous manner (e.g., via Artificial } \\
\text { Neural Networks, ANNs). }\end{array}$ \\
\hline Monitoring & $\begin{array}{l}\text { Assess the durability of improvements with longitudinal data } \\
\text { collected remotely (e.g., via smartphones, tablets, wristbands, } \\
\text { or personal computers). }\end{array}$ \\
\hline Testability & $\begin{array}{l}\text { Work toward building a theoretical framework of cognitive } \\
\text { enhancement, to refine understanding of the underlying } \\
\text { mechanisms and stability of behavioral improvement and neural } \\
\text { changes. }\end{array}$ \\
\hline Collaboration & $\begin{array}{l}\text { Allow higher predictive power across individuals and research } \\
\text { groups by sharing open-source dynamic models (e.g., online } \\
\text { repository). }\end{array}$ \\
\hline
\end{tabular}

As this line or research suggests, understanding the neural bases of atypical reading and attention has important implications for remediation (Shaywitz et al., 2004). The early identification of children at risk for reading and attention deficits can help to provide them with appropriate resources and learning material. By identifying individuals whose reading or attention difficulties are the result of genetic differences in brain processing, such remediation techniques may be specifically tailored to maximize their effectiveness. Cognitive remediation programs have been shown to alleviate some of the symptoms associated with these disorders (Temple et al., 2003; Franceschini et al., 2013), but have yet to induce substantial and durable gains. Given these limitations, novel cognitive intervention paradigms combining behavioral and neurophysiological mechanisms are promising and could provide further insight into more effective remediation approaches (Diamond and Lee, 2011; Moreau and Conway, 2014).

\section{ECOLOGICAL APPROACHES OF REMEDIATION}

Recent trends in cognitive training have shown promises with programs that can benefit individuals in a broad manner (Diamond and Lee, 2011; Moreau and Conway, 2014). Such ecological approaches are well suited to individuals who do not present particular cognitive deficits, since they provide naturalistic environments to nurture general improvement. For example, this type of approach can allow targeting multiple components, such as cognitive gains and general health improvements in the case of regimens based on physical exercise (Tomporowski et al., 2008; Moreau, 2015). The neurobiological mechanisms underlying such improvements are well understood, and are consistent across animal and human literatures (see for a review Moreau and Conway, 2013). Likewise, seeking cognitive gains via music training has gained traction in recent years, with the added benefit of practicing an activity that is meaningful outside of the training regimen - learning to play an instrument (Kraus and Chandrasekaran, 2010; Moreno et al., 2011). Although the relevance of this approach remains to be established in the remediation of learning disorders (Bailey and Snowling, 2002), the associated changes are potentially durable, with fundamental structural changes in several cortical regions, such as the right precentral gyrus and the primary auditory region. Differences in neural activation can also be found outside auditory and motor areas, for example in bilateral frontolateral and frontomesial regions and in the left posterior pericingulate area (Hyde et al., 2009). In line with the idea of seeking cognitive enhancement through ecological means, there might even be more additional health or cognitive benefits with approaches that can be implemented outdoors (Jha et al., 2007; Berman et al., 2008; Dolgin, 2015).

Cognitive remediation represents a slightly different challenge, as it requires taking into account the specificities of the learning disorder targeted. If one's working memory capacity is insufficient, specific training might be needed to address this limitation, and a more generic approach might lack the 
intensive focus required to remediate impairment. Aside from these considerations regarding content, training and remediation also have fundamental differences in terms of overarching goals - while cognitive training lacks a clear purpose due to unclear mechanisms underlying improvement (Moreau, 2014a) and potential tradeoffs in the abilities targeted (Hills and Hertwig, 2011), cognitive remediation offers an unambiguous objective: allowing the ability or set of abilities that is impaired to be improved so that it no longer impedes learning. This does not necessarily mean that the underlying mechanisms of improvement are better understood, but it allows a more direct assessment of the outcomes of an intervention. As we have mentioned previously, several studies have shown promises in the remediation of dyslexia (Temple et al., 2003) and ADHD (Klingberg et al., 2005), yet this line of work needs to be extended upon, and further replication controlling for potential confounds is required.

\section{TOWARD INDIVIDUALIZED REGIMENS}

What is the future of cognitive remediation programs for dyslexia and ADHD? In our view, one direction that seems inevitable is toward individualized regimens. For decades, psychologists have studied individual differences in cognition - the rationale for this entire field of research, differential psychology, is that although they share important cognitive traits, individuals differ greatly in the way their process the world around them, and that studying these differences is of importance in itself to refine theoretical models of cognition. Consistent with this idea, research on cognitive training regimens is transitioning toward an individualized approach (Moreau, 2014b; Könen and Karbach, 2015), in which individual differences are factored in to determine optimal training content. Indeed, that impairment is typically specific in dyslexia and ADHD does not mean that these specificities are necessarily consistent across all individuals diagnosed with the same disorder. For example, meta-analytic findings do not support the idea that ADHD is a disorder resulting from highly localized deficits (Dickstein et al., 2006); rather, the neural signature of ADHD is more complex, and involves individual specificities. Similar conclusions can be drawn from the study of dyslexics, who are typically identified based on behavioral manifestations, irrespective of betweenindividual consistency in neural substrates (Heim and Keil, 2004). As technological advances allow detecting learning impairment at an early age, remediation programs are bound to shift from a one-size-fits-all approach to individualized regimen targeting children's specific needs and challenges.

\section{REFERENCES}

Alvarez, J. A., and Emory, E. (2006). Executive function and the frontal lobes: a meta-analytic review. Neuropsychol. Rev. 16, 17-42. doi: 10.1007/s11065-0069002-x

American Psychiatric Association [APA] (2013). Diagnostic and Statistical Manual of Mental Disorders, 5th Edn. Washington, DC: American Psychiatric Association.
Importantly, recognizing that individual differences matter in cognitive remediation does not legitimate the absence of empirical evidence for a particular training program - this is often the argument put forward by cognitive training corporations to justify a lack of scientific support for their claims. Rather, the rationale here is that differences across individuals need to inform training regimens to maximize outcomes (see Table 1). For example, software or personal tutors can use progress reports to allocate more time and resources to practice on a specific task or ability, based on clinical evidence for a particular disorder. In practice, this idea also means that a cognitive remediation program can be designed with a common structure for different learning disorders (i.e., core/general components), complemented by content tailored to the deficient or targeted abilities of each individual.

\section{CONCLUDING REMARKS: FROM REMEDIATION TO PREVENTION}

The long-term consequences of cognitive remediation are presently unclear - in the broader field of cognitive enhancement, some have pointed out the limits of our current understanding regarding the underlying mechanisms and potential tradeoffs involved in better cognitive performance (Hills and Hertwig, 2011; Moreau, 2014a). Until we can successfully integrate findings within a theoretical framework of cognitive enhancement, cognitive remediation studies will remain a heterogeneous collection of work potentially tapping into different mechanisms. With this limitation in mind, advances in neuroscience allow detecting potential learning disorders earlier - ultimately, specific remediation programs will strive to prevent difficulties rather than remediate existing disorders. The impact of such interventions is difficult to foresee, as this approach is novel in the remediation of dyslexia and ADHD, but it has the potential to be particularly influential. In addition to clinical benefits, preventing disorders is also a more rational and efficient approach than post-diagnoses remediation, thus offering brighter outlooks to many children, as well as numerous advantages to the community.

\section{ACKNOWLEDGMENTS}

DM and KW are supported by the Campus Link Foundation (grant \#9133-3706255), as well as philanthropic funds from Perpetual Guardian (as trustee of the Lady Alport Barker Trust) and Kelliher Charitable Trust.

Aron, A. R., and Poldrack, R. A. (2005). The cognitive neuroscience of response inhibition: relevance for genetic research in attention-deficit/hyperactivity disorder. Biol. Psychiatry 57, 1285-1292. doi: 10.1016/j.biopsych.2004.10.026

Bailey, P. J., and Snowling, M. J. (2002). Auditory processing and the development of language and literacy. Br. Med. Bull. 63, 135-146. doi: 10.1093/bmb/63.1.135

Barkley, R. A. (1997). Behavioral inhibition, sustained attention, and executive functions: constructing a unifying theory of ADHD. Psychol. Bull. 121, 65-94. doi: 10.1037/0033-2909.121.1.65 
Berman, M. G., Jonides, J., and Kaplan, S. (2008). The cognitive benefits of interacting with nature. Psychol. Sci. 19, 1207-1212. doi: 10.1111/j.14679280.2008.02225.x

Biederman, J. (2005). Attention-deficit/hyperactivity disorder: a selective overview. Biol. Psychiatry 57, 1215-1220. doi: 10.1016/j.biopsych.2004.10.020

Blakemore, S.-J., and Choudhury, S. (2006). Development of the adolescent brain: implications for executive function and social cognition. J. Child Psychol. Psychiatry 47, 296-312. doi: 10.1111/j.1469-7610.2006.01611.x

Bush, G., Valera, E. M., and Seidman, L. J. (2005). Functional neuroimaging of attention-deficit/hyperactivity disorder: a review and suggested future directions. Biol. Psychiatry 57, 1273-1284. doi: 10.1016/j.biopsych.2005. 01.034

Butterworth, B., and Kovas, Y. (2013). Understanding neurocognitive developmental disorders can improve education for all. Science 340, 300-305. doi: 10.1126/science.1231022

Caspi, A., Langley, K., Milne, B., Moffitt, T. E., O’Donovan, M., Owen, M. J., et al. (2008). A replicated molecular genetic basis for subtyping antisocial behavior in children with attention-deficit/hyperactivity disorder. Arch. Gen. Psychiatry 65, 203-210. doi: 10.1001/archgenpsychiatry.2007.24

Castellanos, F. X., and Tannock, R. (2002). Neuroscience of attentiondeficit/hyperactivity disorder: the search for endophenotypes. Nat. Rev. Neurosci. 3, 617-628. doi: 10.1038/nrn896

Clark, K. A., Helland, T., Specht, K., Narr, K. L., Manis, F. R., Toga, A. W., et al. (2014). Neuroanatomical precursors of dyslexia identified from pre-reading through to age 11. Brain 137(Pt 12), 3136-3141. doi: 10.1093/brain/awu229

Cohen, L., and Dehaene, S. (2004). Specialization within the ventral stream: the case for the visual word form area. Neuroimage 22, 466-476. doi: 10.1016/j.neuroimage.2003.12.049

Couto, J. M., Livne-Bar, I., Huang, K., Xu, Z., Cate-Carter, T., Feng, Y., et al. (2010). Association of reading disabilities with regions marked by acetylated H3 histones in KIAA0319. Am. J. Med. Genet. B Neuropsychiatr. Genet. 153B, 447-462. doi: 10.1002/ajmg.b.30999

Cubillo, A., Halari, R., Smith, A., Taylor, E., and Rubia, K. (2012). A review of fronto-striatal and fronto-cortical brain abnormalities in children and adults with Attention Deficit Hyperactivity Disorder (ADHD) and new evidence for dysfunction in adults with ADHD during motivation and attention. Cortex 48, 194-215. doi: 10.1016/j.cortex.2011.04.007

Czamara, D., Tiesler, C. M. T., Kohlböck, G., Berdel, D., Hoffmann, B., Bauer, C.P., et al. (2013). Children with ADHD symptoms have a higher risk for reading, spelling and math difficulties in the GINIplus and LISAplus cohort studies. PLoS ONE 8:e63859. doi: 10.1371/journal.pone.0063859

Del'Homme, M., Kim, T. S., Loo, S. K., Yang, M. H., and Smalley, S. L. (2007). Familial association and frequency of learning disabilities in ADHD sibling pair families. J. Abnorm. Child Psychol. 35, 55-62. doi: 10.1007/s10802-00 6-9080-5

Démonet, J.-F., Taylor, M. J., and Chaix, Y. (2004). Developmental dyslexia. Lancet 363, 1451-1460. doi: 10.1016/S0140-6736(04)16106-0

Diamond, A., and Lee, K. (2011). Interventions shown to aid executive function development in children 4 to 12 years old. Science 333, 959-964. doi: 10.1126/science. 1204529

Dickstein, S. G., Bannon, K., Castellanos, F. X., and Milham, M. P. (2006). The neural correlates of attention deficit hyperactivity disorder: an ALE meta-analysis. J. Child Psychol. Psychiatry 47, 1051-1062. doi: 10.1111/j.14697610.2006.01671.x

Dolgin, E. (2015). The myopia boom. Nature 519, 276-278. doi: 10.1038/519276a

Eden, G. F., Jones, K. M., Cappell, K., Gareau, L., Wood, F. B., Zeffiro, T. A., et al. (2004). Neural changes following remediation in adult developmental dyslexia. Neuron 44, 411-422. doi: 10.1016/j.neuron.2004.10.019

Faraone, S. V., and Mick, E. (2010). Molecular genetics of attention deficit hyperactivity disorder. Psychiatr. Clin. N. Am. 33, 159-180. doi: 10.1016/j.psc.2009.12.004

Foster, L. M., Hynd, G. W., Morgan, A. E., and Hugdahl, K. (2002). Planum temporale asymmetry and ear advantage in dichotic listening in Developmental Dyslexia and Attention-Deficit/Hyperactivity Disorder (ADHD). J. Int. Neuropsychol. Soc. 8, 22-36. doi: 10.1017/S1355617702811031

Franceschini, S., Gori, S., Ruffino, M., Viola, S., Molteni, M., and Facoetti, A. (2013). Action video games make dyslexic children read better. Curr. Biol. 23, 462-466. doi: 10.1016/j.cub.2013.01.044
Gabel, L. A., Gibson, C. J., Gruen, J. R., and LoTurco, J. J. (2010). Progress towards a cellular neurobiology of reading disability. Neurobiol. Dis. 38, 173-180. doi: 10.1016/j.nbd.2009.06.019

Gabrieli, J. D. E. (2009). Dyslexia: a new synergy between education and cognitive neuroscience. Science 325, 280-283. doi: 10.1126/science.1171999

Galaburda, A. M., LoTurco, J., Ramus, F., Fitch, R. H., and Rosen, G. D. (2006). From genes to behavior in developmental dyslexia. Nat. Neurosci. 9, 1213-1217. doi: $10.1038 / \mathrm{nn} 1772$

Gayán, J., Willcutt, E. G., Fisher, S. E., Francks, C., Cardon, L. R., Olson, R. K., et al. (2005). Bivariate linkage scan for reading disability and attentiondeficit/hyperactivity disorder localizes pleiotropic loci. J. Child Psychol. Psychiatry 46, 1045-1056. doi: 10.1111/j.1469-7610.2005.01447.x

Germanò, E., Gagliano, A., and Curatolo, P. (2010). Comorbidity of ADHD and dyslexia. Dev. Neuropsychol. 35, 475-493. doi: 10.1080/87565641.2010. 494748

Giedd, J. N., Castellanos, F. X., Casey, B. J., Kozuch, P., King, A. C., Hamburger, S. D., et al. (1994). Quantitative morphology of the corpus callosum in attention deficit hyperactivity disorder. Am. J. Psychiatry 151, 665-669. doi: 10.1176/ajp.151.5.665

Gogtay, N., Giedd, J. N., Lusk, L., Hayashi, K. M., Greenstein, D., Vaituzis, A. C., et al. (2004). Dynamic mapping of human cortical development during childhood through early adulthood. Proc. Natl. Acad. Sci. U.S.A. 101, 81748179. doi: $10.1073 /$ pnas.0402680101

Goswami, U. (2015). Sensory theories of developmental dyslexia: three challenges for research. Nat. Rev. Neurosci. 16, 43-54. doi: 10.1038/nrn3836

Heim, S., and Keil, A. (2004). Large-scale neural correlates of developmental dyslexia. Eur. Child Adolesc. Psychiatry 13, 125-140. doi: 10.1007/s00787-0040361-7

Hills, T., and Hertwig, R. (2011). Why aren't we smarter already: evolutionary trade-offs and cognitive enhancements. Curr. Dir. Psychol. Sci. 20, 373-377. doi: $10.1177 / 0963721411418300$

Hoeft, F., McCandliss, B. D., Black, J. M., Gantman, A., Zakerani, N., Hulme, C., et al. (2011). Neural systems predicting long-term outcome in dyslexia. Proc. Natl. Acad. Sci. U.S.A. 108, 361-366. doi: 10.1073/pnas.10089 50108

Hoeft, F., Meyler, A., Hernandez, A., Juel, C., Taylor-Hill, H., Martindale, J. L., et al. (2007). Functional and morphometric brain dissociation between dyslexia and reading ability. Proc. Natl. Acad. Sci. U.S.A. 104, 4234-4239. doi: 10.1073/pnas.0609399104

Hyde, K. L., Lerch, J., Norton, A., Forgeard, M., Winner, E., Evans, A. C., et al. (2009). Musical training shapes structural brain development. J. Neurosci. 29, 3019-3025. doi: 10.1523/JNEUROSCI.5118-08.2009

Jha, A. P., Krompinger, J., and Baime, M. J. (2007). Mindfulness training modifies subsystems of attention. Cogn. Affect. Behav. Neurosci. 7, 109-119. doi: 10.3758/CABN.7.2.109

Klingberg, T., Fernell, E., Olesen, P. J., Johnson, M., Gustafsson, P., Dahlström, K., et al. (2005). Computerized training of working memory in children with ADHD-a randomized, controlled trial. J. Am. Acad. Child Adolesc. Psychiatry 44, 177-186. doi: 10.1097/00004583-200502000-00010

Könen, T., and Karbach, J. (2015). The benefits of looking at intraindividual dynamics in cognitive training data. Front. Psychol. 6:615. doi: 10.3389/fpsyg.2015.00615

Kraus, N., and Chandrasekaran, B. (2010). Music training for the development of auditory skills. Nat. Rev. Neurosci. 11, 599-605. doi: 10.1038/nr $\mathrm{n} 2882$

Landerl, K., Fussenegger, B., Moll, K., and Willburger, E. (2009). Dyslexia and dyscalculia: two learning disorders with different cognitive profiles. J. Exp. Child Psychol. 103, 309-324. doi: 10.1016/j.jecp.2009.03.006

Laughlin, S. B., and Sejnowski, T. J. (2003). Communication in neuronal networks. Science 301, 1870-1874. doi: 10.1126/science.1089662

Lou, H. C., Henriksen, L., and Bruhn, P. (1990). Focal cerebral dysfunction in developmental learning disabilities. Lancet (Lond. Engl.) 335, 8-11. doi: 10.1016/0140-6736(90)90136-S

Lyon, G. R., Shaywitz, S. E., and Shaywitz, B. A. (2003). A definition of dyslexia. Ann. Dyslexia 53, 1-14. doi: 10.1007/s11881-003-0001-9

McCrory, E. J., Mechelli, A., Frith, U., and Price, C. J. (2005). More than words: a common neural basis for reading and naming deficits in developmental dyslexia? Brain 128(Pt 2), 261-267. doi: 10.1093/brain/awh340 
Merzenich, M., Wright, B., Jenkins, W., Xerri, C., Byl, N., Miller, S., et al. (1996). Cortical plasticity underlying perceptual, motor, and cognitive skill development: implications for neurorehabilitation. Cold Spring Harb. Symp. Quant. Biol. 61, 1-8. doi: 10.1101/SQB.1996.061. 01.003

Moreau, D. (2014a). Software marketing: can brain training boost cognition? Nature 515, 492. doi: 10.1038/515492c

Moreau, D. (2014b). Making sense of discrepancies in working memory training experiments: a Monte Carlo simulation. Front. Syst. Neurosci. 8:161. doi: 10.3389/fnsys.2014.00161

Moreau, D. (2015). Brains and brawn: complex motor activities to maximize cognitive enhancement. Educ. Psychol. Rev. 27, 475-482. doi: 10.1007/s10648015-9323-5

Moreau, D., and Conway, A. R. A. (2013). Cognitive enhancement: a comparative review of computerized and athletic training programs. Int. Rev. Sport Exerc. Psychol. 6, 155-183. doi: 10.1080/1750984X.2012.758763

Moreau, D., and Conway, A. R. A. (2014). The case for an ecological approach to cognitive training. Trends Cogn. Sci. (Regul. Ed.) 18, 334-336. doi: 10.1016/j.tics.2014.03.009

Moreno, S., Bialystok, E., Barac, R., Schellenberg, E. G., Cepeda, N. J., and Chau, T. (2011). Short-term music training enhances verbal intelligence and executive function. Psychol. Sci. 22, 1425-1433. doi: 10.1177/09567976114 16999

Nicolson, R. I., and Fawcett, A. J. (2008). Dyslexia, Learning, and the Brain. Cambridge, MA: MIT Press.

Overtoom, C. C. E., Kenemans, J. L., Verbaten, M. N., Kemner, C., van der Molen, M. W., van Engeland, H., et al. (2002). Inhibition in children with attention-deficit/hyperactivity disorder: a psychophysiological study of the stop task. Biol. Psychiatry 51, 668-676. doi: 10.1016/S0006-3223(01)0 1290-2

Plomin, R., DeFries, J. C., McClearn, G. E., and McGuffin, P. (2008). Behavioral Genetics. New York, NY: Worth Publishers.

Poelmans, G., Buitelaar, J. K., Pauls, D. L., and Franke, B. (2011). A theoretical molecular network for dyslexia: integrating available genetic findings. Mol. Psychiatry 16, 365-382. doi: 10.1038/mp.2010.105

Pugh, K. (2006). A neurocognitive overview of reading acquisition and dyslexia across languages. Dev. Sci. 9, 448-450; discussion 451-453. doi: 10.1111/j.14677687.2006.00528.x

Raschle, N. M., Chang, M., and Gaab, N. (2011). Structural brain alterations associated with dyslexia predate reading onset. Neuroimage 57, 742-749. doi: 10.1016/j.neuroimage.2010.09.055

Richlan, F. (2012). Developmental dyslexia: dysfunction of a left hemisphere reading network. Front. Hum. Neurosci. 6:120. doi: 10.3389/fnhum.2012. 00120

Rubia, K., Smith, A. B., Brammer, M. J., Toone, B., and Taylor, E. (2005). Abnormal brain activation during inhibition and error detection in medicationnaive adolescents with ADHD. Am. J. Psychiatry 162, 1067-1075. doi: 10.1176/appi.ajp.162.6.1067

Rumsey, J. M., Horwitz, B., Donohue, B. C., Nace, K., Maisog, J. M., and Andreason, P. (1997). Phonological and orthographic components of word recognition. A PET-rCBF study. Brain 120(Pt 5), 739-759.

Scerri, T. S., and Schulte-Körne, G. (2010). Genetics of developmental dyslexia. Eur. Child Adolesc. Psychiatry 19, 179-197. doi: 10.1007/s00787-00 9-0081-0

Shafritz, K. M., Marchione, K. E., Gore, J. C., Shaywitz, S. E., and Shaywitz, B. A. (2004). The effects of methylphenidate on neural systems of attention in attention deficit hyperactivity disorder. Am. J. Psychiatry 161, 1990-1997. doi: 10.1176/appi.ajp.161.11.1990

Shaw, P., Eckstrand, K., Sharp, W., Blumenthal, J., Lerch, J. P., Greenstein, D., et al. (2007). Attention-deficit/hyperactivity disorder is characterized by a delay in cortical maturation. Proc. Natl. Acad. Sci. U.S.A. 104, 19649-19654. doi: 10.1073/pnas.0707741104

Shaywitz, B. A., Lyon, G. R., and Shaywitz, S. E. (2006). The role of functional magnetic resonance imaging in understanding reading and dyslexia. Dev. Neuropsychol. 30, 613-632. doi: 10.1207/s15326942dn3001_5

Shaywitz, B. A., Shaywitz, S. E., Blachman, B. A., Pugh, K. R., Fulbright, R. K., Skudlarski, P., et al. (2004). Development of left occipitotemporal systems for skilled reading in children after a phonologically- based intervention. Biol. Psychiatry 55, 926-933. doi: 10.1016/j.biopsych.2003. 12.019

Shaywitz, B. A., Skudlarski, P., Holahan, J. M., Marchione, K. E., Constable, R. T., Fulbright, R. K., et al. (2007). Age-related changes in reading systems of dyslexic children. Ann. Neurol. 61, 363-370. doi: 10.1002/ana. 21093

Skoyles, J. R., and Skottun, B. C. (2009). Conflicting data about dyslexia's cause. Science 326, 228-229. doi: 10.1126/science.326_228b

Smith, S. D. (2011). Approach to epigenetic analysis in language disorders. J. Neurodev. Disord. 3, 356-364. doi: 10.1007/s11689-011-9099-y

Stefanatos, G. A., and Wasserstein, J. (2001). Attention deficit/hyperactivity disorder as a right hemisphere syndrome. Selective literature review and detailed neuropsychological case studies. Ann. N. Y. Acad. Sci. 931, 172-195. doi: 10.1111/j.1749-6632.2001.tb05779.x

Stiles, J., and Jernigan, T. L. (2010). The basics of brain development. Neuropsychol. Rev. 20, 327-348. doi: 10.1007/s11065-010-9148-4

Suskauer, S. J., Simmonds, D. J., Fotedar, S., Blankner, J. G., Pekar, J. J., Denckla, M. B., et al. (2008). Functional magnetic resonance imaging evidence for abnormalities in response selection in attention deficit hyperactivity disorder: differences in activation associated with response inhibition but not habitual motor response. J. Cogn. Neurosci. 20, 478-493. doi: 10.1162/jocn.2008. 20032

Szaflarski, J. P., Schmithorst, V. J., Altaye, M., Byars, A. W., Ret, J., Plante, E., et al. (2006). A longitudinal functional magnetic resonance imaging study of language development in children 5 to 11 years old. Ann. Neurol. 59, 796-807. doi: $10.1002 /$ ana.20817

Temple, E. (2002). Brain mechanisms in normal and dyslexic readers. Curr. Opin. Neurobiol. 12, 178-183. doi: 10.1016/S0959-4388(02)00303-3

Temple, E., Deutsch, G. K., Poldrack, R. A., Miller, S. L., Tallal, P., Merzenich, M. M., et al. (2003). Neural deficits in children with dyslexia ameliorated by behavioral remediation: evidence from functional MRI. Proc. Natl. Acad. Sci. U.S.A. 100, 2860-2865. doi: 10.1073/pnas.00300 98100

Tomporowski, P. D., Davis, C. L., Miller, P. H., and Naglieri, J. A. (2008). Exercise and children's intelligence, cognition, and academic achievement. Educ. Psychol. Rev. 20, 111-131. doi: 10.1007/s10648-007-9057-0

Turkeltaub, P. E., Gareau, L., Flowers, D. L., Zeffiro, T. A., and Eden, G. F. (2003). Development of neural mechanisms for reading. Nat. Neurosci. 6, 767-773. doi: 10.1038/nn1065

Vidyasagar, T. R., and Pammer, K. (2010). Dyslexia: a deficit in visuo-spatial attention, not in phonological processing. Trends Cogn. Sci. (Regul. Ed.) 14, 57-63. doi: 10.1016/j.tics.2009.12.003

Waldie, K. E. (2002). "Reading with the right hemisphere: from normal development to dyslexia," in Advances in Psychology Research, Vol. 9, ed. S. P. Shohov (New York, NY: Nova Science Publishers, Inc), $157-184$.

Waldie, K. E., Haigh, C. E., Badzakova-Trajkov, G., Buckley, J., and Kirk, I. J. (2013). Reading the wrong way with the right hemisphere. Brain Sci. 3, 1060-1075. doi: 10.3390/brainsci3031060

Waldie, K. E., and Hausmann, M. (2010). Right fronto-parietal dysfunction in children with ADHD and developmental dyslexia as determined by line bisection judgements. Neuropsychologia 48, 3650-3656. doi: 10.1016/j.neuropsychologia.2010.08.023

Willcutt, E. G., Betjemann, R. S., McGrath, L. M., Chhabildas, N. A., Olson, R. K., DeFries, J. C., et al. (2010). Etiology and neuropsychology of comorbidity between RD and ADHD: the case for multiple-deficit models. Cortex 46, 1345-1361. doi: 10.1016/j.cortex.2010.06.009

Willcutt, E. G., and Pennington, B. F. (2000a). Comorbidity of reading disability and attention-deficit/hyperactivity disorder: differences by gender and subtype. J. Learn. Disabil. 33, 179-191. doi: 10.1177/0022219400033 00206

Willcutt, E. G., and Pennington, B. F. (2000b). Psychiatric comorbidity in children and adolescents with reading disability. J. Child Psychol. Psychiatry 41, 10391048. doi: 10.1111/1469-7610.00691

Ziegler, A., König, I. R., Deimel, W., Plume, E., Nöthen, M. M., Propping, P., et al. (2005). Developmental dyslexia-recurrence risk estimates from a german bicenter study using the single proband sib pair design. Hum. Hered. 59, 136-143. doi: $10.1159 / 000085572$ 
Ziegler, J. C., and Goswami, U. (2005). Reading acquisition, developmental dyslexia, and skilled reading across languages: a psycholinguistic grain size theory. Psychol. Bull. 131, 3-29. doi: 10.1037/0033-2909.131.1.3

Conflict of Interest Statement: The authors declare that the research was conducted in the absence of any commercial or financial relationships that could be construed as a potential conflict of interest.

The reviewer, Adriana Marques de Oliveira, and handling editor declared their shared affiliation, and the handling editor states that the process nevertheless met the standards of a fair and objective review.
The reviewer, Vera Lúcia Orlandi Cunha, and handling editor declared their shared affiliation, and the handling editor states that the process nevertheless met the standards of a fair and objective review.

Copyright (c) 2016 Moreau and Waldie. This is an open-access article distributed under the terms of the Creative Commons Attribution License (CC BY). The use, distribution or reproduction in other forums is permitted, provided the original author(s) or licensor are credited and that the original publication in this journal is cited, in accordance with accepted academic practice. No use, distribution or reproduction is permitted which does not comply with these terms. 